\title{
Improved Earthquake Input Energy Spectra for Single Directional Earthquake Excitation
}

\author{
Jian-Yi YANG ${ }^{1, a}$, Feng WANG ${ }^{1, b,{ }^{*}, \text { Wen-Xiong ZHOU }}{ }^{1, c}$, Xiu-Qi CUI ${ }^{1, d}$ \\ ${ }^{1}$ College of Architecture \& Civil Engineering, Dalian Nationalities University, Dalian 116650, China \\ aYjydlnu@163.com , bwin_0803@163.com, 'zwxdlnu@163.com, ${ }^{\mathrm{d}} \mathrm{cuixq2014@126.com}$ \\ ${ }^{*}$ Corresponding author
}

Keywords: Earthquake Input Energy, Ductility Factor, Strength Reduction Factors, Nonlinear Time History Analysis.

\begin{abstract}
Cumulative energy response spectra can generally be used to estimate earthquake energy demand of structures. Some research findings show that the earthquake input energy demand is stable than other forms of energy demand, so it is important for scholars to research earthquake input energy demand and establish earthquake input energy spectra. For the purpose of obtaining the mean spectra, earthquake input energy is normalized as the ratio of earthquake input energy to square of peak ground acceleration. The energy balance equation is established based on the SDOF system, and the improved earthquake input energy spectral model is presented. The earthquake motion records of three kinds of soil sites are selected as the earthquake excitations of the SDOF system, and the mean spectra is established by nonlinear time history analysis. The influences of natural period, ductility factor and soil site on earthquake input energy are analyzed.
\end{abstract}

\section{Introduction}

Curretly, energy-based seismic design (EBSD) has been widely developed[1, 2, 3], in which the influence of duration-related cumulative damage is considred, and that is difficult to include in other methods. The regularities of energy demand can be obtained by analyzing the relationship between energy and natural period which can be called energy spectra. In recent years, researches about energy spectra have been developed rapidly, such as earthquake input energy spectra[4], hysteretic energy spectra[5], equivalent velocity spectra, momentary absorbed energy spectra[6], momentary input energy spectra, inelastic cyclic demand spectra[7] etc. Some analyses [8] show that the earthquake input energy demand is stable than other forms of energy demand. So, it is important to analyze earthquake input energy demand and establish earthquake input energy spectra. The aim of this research is to present an improved earthquake input energy spectra, and analyze the influence factors of the spetra.

\section{The Model of Improved Earthquake Input Energy}

Considering a SDOF system under earthquake acceleration $\ddot{u}_{\mathrm{g}}(t)$, the equation of motion can be expressed as:

$$
m \ddot{u}(t)+c \dot{u}(t)+f(t)=-m \ddot{u}_{g}(t)
$$

in which $m$ and $c$ are mass and damping of the system, respectively; $f(t)$ is restoring force of the system, and the property of restoring force is defined as ideal elastic-plastic; $\ddot{u}(t)$ and $\dot{u}(t)$ are acceleration and velocity of the system. The corresponding energy balance equation of the system can be deduced as:

$$
\int_{0}^{t} \ddot{u}(t) \dot{u}(t) d t+2 \xi \omega \int_{0}^{t} \dot{u}(t) \dot{u}(t) d t+\omega^{2} \int_{0}^{t} \frac{f(t)}{k} \dot{u}(t) d t=-\int_{0}^{t} \ddot{u}_{g}(t) \dot{u}(t) d t
$$

where $u(t)$ is displacement of the system; $\omega, \xi$ and $k$ are natural vibration frequency, damping ratio and elastic stiffness of the system, respectively, in which $\omega$ equals $(k / m)^{0.5}, 2 \xi \omega$ equals $\mathrm{c} / \mathrm{m}$. 
Relative displacement $\mu(t)$ is defined as $\mu(t)=u(t) / u_{y i e}$, in which $u_{y i e}$ is yield displacement, and then $u(t)$ can be replaced by $\mu(t) \cdot u_{y i e}$, so the energy balance energy is rewritened as:

$$
u_{y i e}^{2} \int_{0}^{t} \ddot{\mu}(t) \dot{\mu}(t) d t+2 \xi \omega u_{y i e}^{2} \int_{0}^{t} \dot{\mu}(t) \dot{\mu}(t) d t+\omega^{2} u_{y i e}^{2} \int_{0}^{t} \frac{f(t)}{f_{y i e}} \dot{\mu}(t) d t=-u_{y i e} \int_{0}^{t} \ddot{u} g(t) \dot{\mu}(t) d t
$$

in which $f_{y i e}$ is yield force of the system, and $f_{\text {yie }}$ equals $k \cdot u_{y i e}$.

The strength reduction factors can be expressed as:

$$
R=\frac{f_{e, \max }}{f_{y i e}}
$$

in which $f_{e \text {,max }}$ is the peak of elastic force of the system, and $f_{e \text {, max }}$ can be determined by the following equation:

$$
f_{e, \max }=m \cdot \beta \cdot \max \left|\ddot{u}_{g}(t)\right|
$$

in which $\beta$ is elastic amplification coefficient spectra, and $\beta$ is the function of $\omega$. Eq. 5 is substituted into Eq. 4 , and $f_{y i e}$ is replaced by $m \omega^{2} u_{y i e}$, the yield displacement $u_{y i e}$ of the system can be expressed as:

$$
u_{\text {yie }}=\frac{\beta \cdot \max \left|\ddot{u}_{g}(t)\right|}{\omega^{2} \cdot R}
$$

Eq. 6 is substituted into Eq.3, and then the energy balance equation is rewritened as:

$$
\begin{aligned}
& \frac{\beta^{2}\left(\max \left|\ddot{u}_{g}(t)\right|\right)^{2}}{\omega^{4} R^{2}} \int_{0}^{t} \ddot{\mu}(t) \dot{\mu}(t) d t+\frac{2 \xi \beta^{2}\left(\max \left|\ddot{u}_{g}(t)\right|\right)^{2}}{\omega^{3} R^{2}} \int_{0}^{t} \dot{\mu}(t) \dot{\mu}(t) d t+\frac{\beta^{2}\left(\max \left|\ddot{u}_{g}(t)\right|\right)^{2}}{\omega^{2} R^{2}} \int_{0}^{t} \frac{f(t)}{f_{y i e}} \dot{\mu}(t) d t \\
& =-\frac{\beta\left(\max \left|\ddot{u}_{g}(t)\right|\right)^{2}}{\omega^{2} R} \int_{0}^{t} \frac{\ddot{u}_{g}(t)}{\max \left|\ddot{u}_{g}(t)\right|} \dot{\mu}(t) d t
\end{aligned}
$$

The earthquake input energy $E_{l}(t)$ of the system under earthquake excitation can be expressed as:

$$
E_{I}(t)=-\frac{\beta\left(\max \left|\ddot{u}_{g}(t)\right|\right)^{2}}{\omega^{2} R} \int_{0}^{t} \frac{\ddot{u}_{g}(t)}{\max \left|\ddot{u}_{g}(t)\right|} \dot{\mu}(t) d t
$$

For the purpose of statistics, earthquake input energy is normalized as $e_{I}(t)=E_{I}(t) /\left(\max \left|\ddot{u}_{g}(t)\right|\right)^{2}$, and then $e_{I}(t)$ is expressed as:

$$
e_{I}(t)=-\frac{\beta}{\omega^{2} R} \int_{0}^{t} \frac{\ddot{u}_{g}(t)}{\max \left|\ddot{u}_{g}(t)\right|} \dot{\mu}(t) d t
$$

The duration of a earthquake motion is expressed as $t_{0}$. Various $e_{I}\left(t_{0}\right)$ are plotted as a function of natural period $T$ where $T$ equals $2 \pi / \omega$, the improved earthquake input energy spectra IEIES can then be expressed as:

$$
\operatorname{IEIES}(T, \mu)=-\frac{\beta T}{4 \pi^{2} R} \int_{0}^{t_{0}} \frac{\ddot{u}_{g}(t)}{\max \left|\ddot{u}_{g}(t)\right|} \dot{\mu}(t) d t ; \quad \mu=\max \left|\mu\left(t_{0}\right)\right|
$$

in which $\mu$ is ductility factor of the system under earthquake excitation, and $\mu$ equals $\max |u(t)| / u_{y i e}$ or $\max |\mu(t)|$.The Eq.10 can be regarded as the equation of improved earthquake input energy spectra. 


\section{Analysis of Improved Earthquake Input Energy Spectra}

The earthquake motion records for hard soil site $\left(V_{s}=360-750 \mathrm{~m} / \mathrm{s}\right)$, intermediate soil site $\left(V_{\mathrm{s}}=180-360\right.$ $\mathrm{m} / \mathrm{s})$ and soft soil site $\left(\mathrm{V}_{\mathrm{s}}<180 \mathrm{~m} / \mathrm{s}\right)$, corresponding to $\mathrm{B}, \mathrm{C}$ and D respectively for USGS, are selected [9] for establishing the mean spectra of improved earthquake input energy.

The mean spectra of improved earthquake input energy of constant ductility factors for the three kinds of soil sites are illustrated in Fig.1, in which the ductility factors $\mu$ are respectively assumed as 1.5, 2, 3, 4, 5 and 6. As shown in Fig.1, the spectral curves of the three soil sites are all composed of upward stage, peak platform stage and downward stage, and the period range of each stage is different for different ductility factors. Considering $\mu$ equal 2 , the period ranges of spectral curve stages are given as: As for hard soil site, the period ranges for the three curve stages are about $0 \sim 0.5 \mathrm{sec}, 0.5 \sim 0.9 \mathrm{sec}$ and $0.9 \sim 7.0 \mathrm{sec}$, respectively; as for intermediate soil site, the period ranges for the three curve stages are about $0 \sim 0.6 \mathrm{sec}$, $0.6 \sim 1.6 \mathrm{sec}$ and 1.6 7.0sec, respectively; as for soft soil site, the period ranges for the three curve stages are about $0 \sim 3.4 \mathrm{sec}, 3.4 \sim 6.0 \mathrm{sec}$ and $6.0 \sim 7.0 \mathrm{sec}$, respectively. The upward stage of soft soil site is more gentle than that of hard soil site and intermediate soil site, and the downward stage of hard soil site is more sharply than that of intermediate soil site and soft soil site. In addition, the influence of ductility factor on earthquake input energy demand is obviously, and the trend is that the eathquake input energy demands decrease gradually with the increase of ductility factors in peak platform stage and downward stage of spectral curves. For solving hysteretic energy through earthquake input energy spectra, the ratio of hysteretic energy $E_{H}$ to earthquake input energy $E_{I}$ is defined as $\alpha$, and the $\alpha$ spectra of constant ductility factors are illustrated in Fig.2. As shown in Fig.2, for the three kinds of soil sites, the $\alpha$ (or $\left.E_{H} / E_{I}\right)$ tend to level with the period increase, and $\alpha$ (or $\left.E_{H} / E_{I}\right)$ increase gradually with the increase of ductility factors.

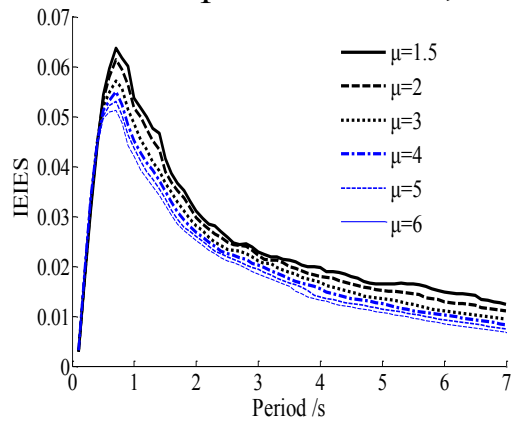

(a) Hard soil site

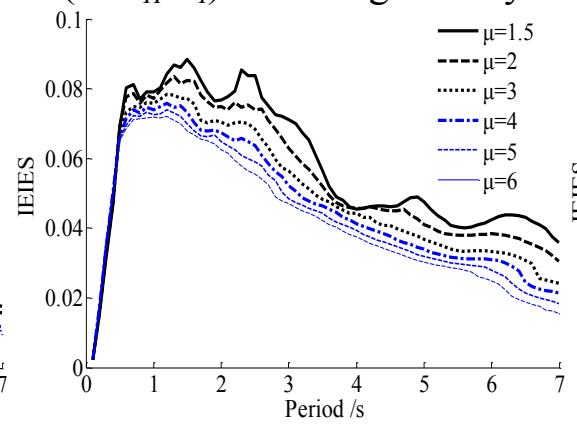

(b) Intermediate soil site

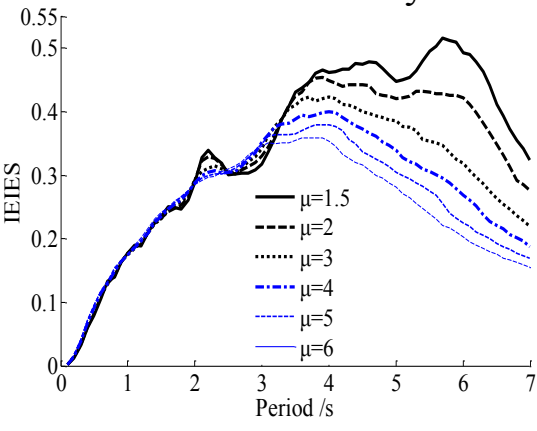

(c) Soft soil site

Fig. 1 Improved Earthquake Input Energy Spectra(IEIES)

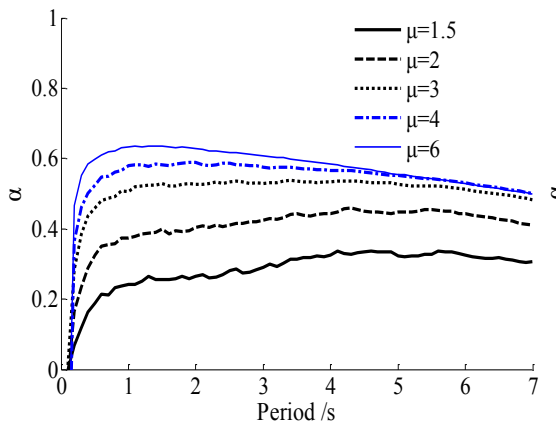

(a) Hard soil site

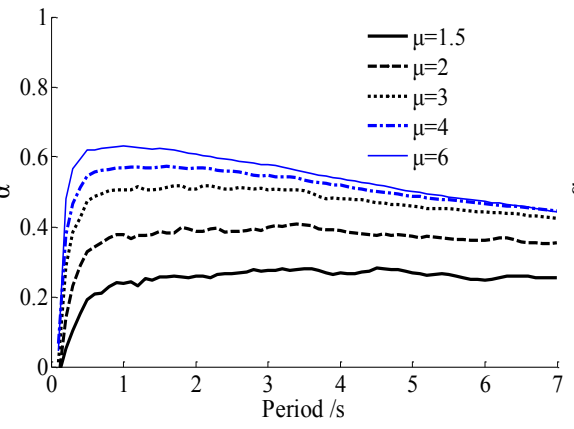

(b) Intermediate soil site

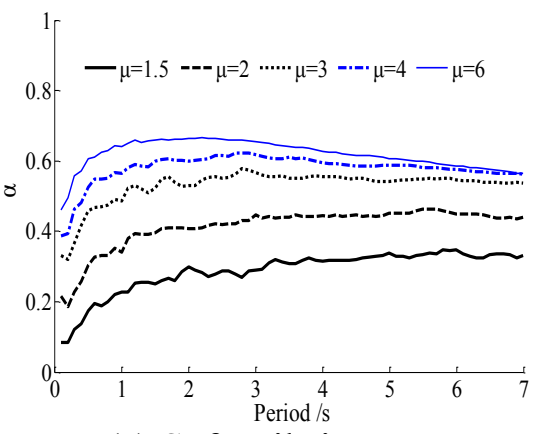

(c) Soft soil site

Fig. 2 The $\alpha$ Spectra $(\alpha=E H / E I)$

\section{Conclusion}

The improved earthquake input energy spectra is presented, and mean spectra are established by nonlinear time history analysis based on the selected earthquake motion records. The influences of ductility factor and soil site on earthquake input energy demands are analyzed. In additon, the $\alpha$ specra are established for the purpose of solving hysteretic energy $E_{H}$ through earthquake input energy $E_{I}$. Some conclusions are given as follows: 
(1) The improved earthquake input energy spectra have the typical spectral pattern features of soil sites. The spectral curves of the three kinds of soil sites are all composed of upward stage, peak platform stage and downward stage, and the control periods of each stage are affected obviously by ductility factors.

(2) The demands of earthquake input energy increase gradually with the increase of ductility factors.

(3) In the $\alpha$ specra, the $\alpha$ tend to level with the period increase, and $\alpha$ increase gradually with the increase of ductility factors $\mu$.

\section{Acknowledgment}

This research was financially supported by the National Natural Science Foundation of China (Grant No. 51478091), the National Natural Science Foundation of China (Grant No. 51108067), Program for Liaoning Excellent Talents in University (Grant No. LJQ2014139).

\section{References}

[1]T. Prasanth, S. Ghosh, K. R. Collins, Estimation of hysteretic energy demand using concepts of modal pushover analysis, Earthquake Engineering and Structural Dynamics, 37(2008), 975-990.

[2]A. Benavent-Climent, A energy-based method for seismic retrofit of existing frames using hysteretic dampers, Soil Dynamics and Earthquake Engineering, 31(2011), 1385-1396.

[3]A. Habibi, R. W. K. Chan and F. Albermani, Energy-based design method for seismic retrofitting with passive energy dissipation systems, Engineering Structures, 46(2013), 77-86.

[4]A. Benavent-Climent, F. Lopez-Almanse, D. A. Bravo-Gonzalez, Design energy input spectra for moderate-to-high seismicity regions based on Colombian earthquakes, Soil Dynamics and Earthquake Engineering, 30(2011), 1129-1148.

[5]R. Riddell, J. E. Garcia, Hysteretic energy spectrum and damage control, Earthquake Engineering and Structural Dynamics, 30(2001), 1791-1816.

[6]Y. Hagiwara, Momentary energy absorption and effective loading cycles of structures during earthquakes, The 15th World Conference on Earthquake Engineering, 2000, Auckland, New Zealand, January.

[7]S. K. Kunnanth, H. Chai, Cumulative damage-based inelastic cyclic demand spectrum, Earthquake Engineering and Structural Dynamics, 33(2004), 499-520.

[8]H. Kuwamura, T. V. Galambos, Earthquake load for structural reliability, Journal of Structural Engineering, ASCE, 115(1989), 1446-1462.

[9]F. Wang, Studies on performance-based seismic design methods of structures subjected to multidimensional earthquake excitations. PHD Dissertation, Dalian University of Technology, Dalian, China, 2007. 